\title{
Prevalence, determinants and impacts of khat chewing among professional drivers in Southwestern Saudi Arabia
}

NabilJ. Awadalla ${ }^{1,2}$ and Hassan A. Suwaydi ${ }^{3}$

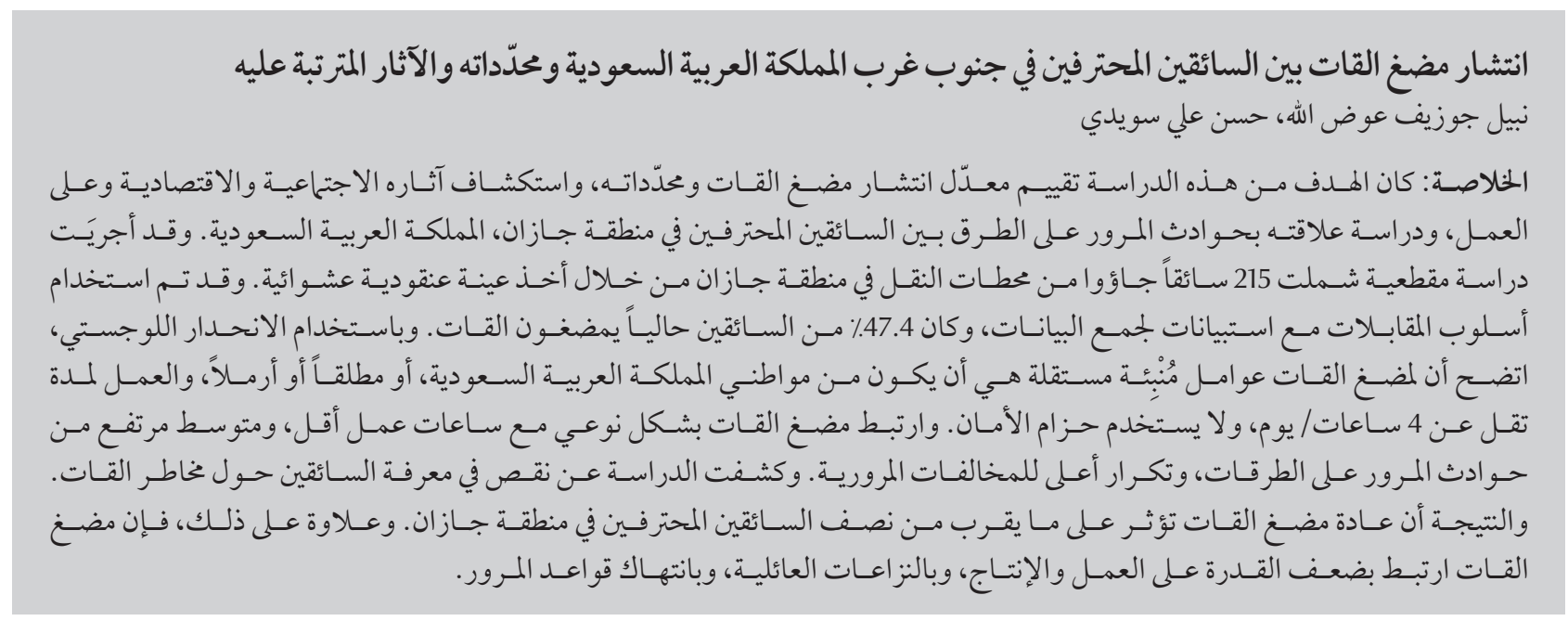

ABSTRACT The objective of this study was to assess the prevalence and determinants of khat chewing, and explore its social, economic and work impacts and examine its relation with road traffic accidents (RTA) among professional drivers in Jazan region, Saudi Arabia. A cross-sectional study was conducted on 215 drivers recruited from transport stations in Jazan region by random cluster sampling. An interview questionnaire was utilized for data collection, and $47.4 \%$ of drivers were currently khat chewers. Using a logistic regression, the independent predictors of khat chewing were being a citizen of Saudi Arabia, divorced or widowed, working for less than 4 hours/day, and a non-seatbelt user. Khat chewing was significantly associated with shorter working hours; higher average number of significant RTA, and higher frequency of traffic violation. In conclusion, khat chewing habit affected almost half of the professional drivers in Jazan area. Moreover, khat chewing was associated with impaired working ability and productivity, family conflicts, and violation of traffic rules.

Prévalence, déterminants et conséquences de la consommation de khat chez les chauffeurs professionnels dans le sud-ouest de l'Arabie saoudite

RÉSUMÉ La présente étude avait pour objectif d'évaluer la prévalence et les déterminants de la consommation de khat, d'étudier ses conséquences sociales, économiques et dans le milieu du travail, et d'examiner sa relation avec les accidents de la circulation parmi les chauffeurs professionnels de la région de Jazan, en Arabie saoudite. Une étude transversale a été réalisée auprès de 215 chauffeurs sélectionnés dans des terminaux de transport de la région de Jazan sur la base d'un sondage aléatoire en grappe. Un questionnaire d'entrevue a été utilisé pour la collecte des données, et $47,4 \%$ des chauffeurs ont déclaré consommer du khat au moment de leur participation à l'enquête. La régression logistique a révélé que les variables indépendantes étaient le fait d'être citoyen saoudien, divorcé ou veuf, de travailler moins de 4 heures par jour, et de ne pas porter sa ceinture de sécurité. La consommation de khat était fortement associée à un faible nombre d'heures travaillées, à un nombre moyen plus élevé d'accidents de la circulation graves, et à une fréquence plus importante des enfreintes du code de la route. En conclusion, I'habitude de consommation de khat affectait près de la moitié des chauffeurs professionnels de la région de Jazan. En outre, la consommation de khat a été associée à une détérioration de l'aptitude au travail et de la productivité, à des conflits familiaux, et à des infractions du code de la route.

${ }^{'}$ Family and Community Medicine Department, College of Medicine, King Khalid University, Abha, Saudi Arabia (Correspondence to: N.J. Awadalla: njgirgis@yahoo.co.uk). ${ }^{2}$ Community Medicine Department, College of Medicine, Mansoura University, Mansoura, Egypt. ${ }^{3}$ Saudi Board of Family Medicine, Abha Program, Abha, Saudi Arabia.

Received: 16/12/15; accepted: 24/10/16 


\section{Introduction}

Historically, khat grew wild in countries bordering the Red Sea and along the east coast of Africa (1). In Saudi Arabia khat cultivation and consumption are forbidden and the ban is strictly enforced (2), and this has been generally accepted by the population, with the exception of people in the southwestern region of Jazan. In this area, which shares a border with Yemen, khat has been cultivated for centuries and its use is still widespread in the city of Jazan and the surrounding rural areas (3).

The prevalence of khat chewing varies depending on sociocultural habits, availability of khat and law enforcement. An estimated 10 million people worldwide chew khat leaf daily (4). In Jazan Region, the current prevalence of khat chewing among the general population is reported to be $48.7 \%$ (5). There is growing evidence that the new generation of students favours the ban on khat, even though they continue to chew the leaves before examinations (6). The overall prevalence among students is $21.4 \%$ (7). In contrast, there are no available data on its prevalence among professional drivers.

The most important reported motivating factors for khat chewing are the sense of stimulation and social recreation. Khat chewers claim that it heightens the sense of increased energy levels, alertness, ability to concentrate, improved self-esteem and increased libido (8). Also, it maintains social contact as a socializing herb (9).

Several studies have indicated the adverse effects of habitual khat chewing on mental, physical and social wellbeing (10-18). Socially, family life is harmed because of neglect, dissipation of family income and inappropriate behaviour such as drug use, smoking, alcohol and risky sexual behaviour (2).

Khat chewing has been found to decrease the work capability and increase the rate of accidents (19). The problem of road traffic accidents is becoming an internationally recognized concern and is a major cause of morbidity and mortality in Saudi Arabia. Most of the road traffic accidents are related to driver error and $\sim 50 \%$ are associated with excessive speed and violation of safety rules (20). Khat chewing may be associated with a misplaced sense of alertness and may cause hallucinations (21).

The objectives of this study were to assess the prevalence of khat chewing among professional drivers in Jazan Region, evaluate the determinants of khat chewing among them, and explore the impact of khat chewing on work ability, road traffic accidents and violations, and socioeconomic aspects.

\section{Methods}

\section{Study sample and design}

A cross-sectional study was carried out on a randomly selected, representative sample of professional drivers from Jazan Region. Jazan is one of the smallest provinces of Saudi Arabia and is located just north of Yemen. It is subdivided into 14 governorates and the capital is the city of Jazan. The professional drivers were identified as people who were paid to drive a vehicle, including taxis, buses and heavy good vehicles.

The minimum sample size of 196 drivers was calculated according to the formula of Swanson and Cohen (22), with an anticipated $48 \%$ of the population chewing khat (5), and absolute precision of $7 \%$ at $95 \%$ confidence. To account for possible nonresponse, a total of 215 drivers were initially planned for the study.

Proportional allocation, random cluster sampling was used to select the study population. The proportional factor adopted was calculated by dividing the total population in each governorate by the total populations in the selected governorates. Besides Jazan Governorate (255340 individuals), 5 of the remaining 13 governorates of Jazan
Region were randomly selected by simple random technique. These included Sabya (198086 individuals), Abu Arish (128 447), Samtah (123 943), Ahad Almasarihah (70 038) and Al-ddarb (52 062). The required number of drivers from each governorate was calculated by multiplying the proportional factor by the planned sample size. The required drivers from each governorate were collected from bus and taxi stations and companies with heavy goods vehicles through cluster sampling on first available basis till completion of the sample for each particular governorate.

\section{Study tools and data collection}

All the participants were interviewed personally in their working places and were asked to complete an anonymous questionnaire composed of the following sections:

- sociodemographic questions such as age, area of residence, nationality, marital status and educational level;

- questions about occupation such as type of vehicle, duration of work, average working hours, use of seatbelt and impact of khat chewing on work ability;

- questions to assess khat chewing habits, including onset, frequency, place of session, cost per month in Saudi riyal and US dollars, quantity of khat used, duration of session, other associated habits or addictions, attempted cessation, and times of trouble with family;

- questions about motivating factors for khat chewing, including increased alertness and concentration, taste, increased energy, feeling refreshed, increased self-esteem and sexual desire, fear of withdrawal symptoms, and promotion of social discussion;

- questions to assess the history of road traffic accidents and traffic violations in the previous month; significant accidents were considered to be those that required hospital admission for 
$>24$ hours or were associated with fracture, disability or loss of an organ.

\section{Data entry and analysis}

We used SPSS version 18.0 for data entry and analysis. Descriptive statistics were presented as number and percentage for categorical data and mean and standard deviation (SD) for continuous data. $\chi^{2}$ tests were used for the association between categorical variables. Significant factors predicting khat chewing on univariate analysis were entered into multiple logistic regression analysis to establish the independent predictors of khat chewing. Odds ratios (ORs) and 95\% confidence intervals were calculated. $P<0.05$ was considered statistically significant.

\section{Ethics}

The study was approved by the Ethics Committee of King Khalid University. Oral informed consent was obtained from the respondents after explaining the importance of the study. Confidentiality and privacy were guaranteed for all participants.

\section{Results}

The study included 215 drivers whose sociodemographic characteristics are summarized in Table 1 . Their age ranged between 22 and 89 years with an average of 47.8 (11.9) years. They were recruited according to the proportion of the population of the 6 governorates. Most participants were Saudi (82.8\%) and married (88.2\%). Most of them (76.3\%) had an educational level that ranged between primary and secondary schooling. The age and area of residence of the drivers were not significantly associated with khat chewing. Saudi drivers reported a significantly higher rate of khat chewing compared to non-Saudi drivers (55.6\% vs $8.1 \%, P<0.001)$. Also, divorced/widowed drivers reported a significantly higher rate of khat chewing compared to single or married drivers (100\% vs $47.4 \%$ and $45.8 \%$, respectively, $P=0.032)$.

Almost two-thirds of the drivers (65.6\%) had chewed khat, while 47.4\% were currently khat chewers (Table 2 ). The average age at onset of chewing khat was at 23.1 (7.1) years with a median of 20.0 years; $48 \%$ started after the age of 20 years and $17.6 \%$ started at $\leq 15$ years. The most frequent reasons expressed for continuing chewing khat were promoting dialogue and social discussion (79.4\%), making them feel refreshed (54.9\%) and increased energy (47.1\%). More than a third of the participants (38.2\%) reported khat chewing 1 day per week, whereas $11.8 \%$ of them reported its daily use. The median cost of khat chewing was 600 Saudi riyal (US\$160) per month and $47.1 \%$ of

\begin{tabular}{|c|c|c|c|}
\hline \multirow[t]{2}{*}{ Characteristics } & $\begin{array}{c}\text { Total } \\
(n=215)\end{array}$ & $\begin{array}{l}\text { Current khat chewer } \\
\qquad(n=102)\end{array}$ & $P$-value \\
\hline & $n(\%)$ & $n(\%)$ & \\
\hline \multicolumn{4}{|l|}{ Age (yr) } \\
\hline Mean (SD) & $47.8(11.9)$ & $46.32(12.1)$ & 0.09 \\
\hline$\leq 45$ & 79 (36.8) & 39 (49.4) & \\
\hline $46-59$ & $102(47.4)$ & $48(47.1)$ & 0.872 \\
\hline$\geq 60$ & $34(15.8)$ & $15(44.1)$ & \\
\hline \multicolumn{4}{|l|}{ Area of residence } \\
\hline Jazan & $63(29.3)$ & $30(47.6)$ & \\
\hline Sabya & $51(23.7)$ & $27(52.9)$ & \\
\hline Abu Arish & 32 (14.9) & $12(37.5)$ & 0.196 \\
\hline Samtah & $28(13.0)$ & $18(64.3)$ & \\
\hline Ahad Almasarihah & $27(12.6)$ & $9(33.3)$ & \\
\hline Al-ddarb & $14(6.5)$ & $6(42.9)$ & \\
\hline \multicolumn{4}{|l|}{ Nationality } \\
\hline Saudi & $178(82.8)$ & $99(55.6)$ & $<0.001$ \\
\hline Non-Saudi & $37(17.2)$ & $3(8.1)$ & \\
\hline \multicolumn{4}{|l|}{ Marital status } \\
\hline Single & 19 (8.8) & $9(47.4)$ & \\
\hline Married & $190(88.4)$ & $87(45.8)$ & 0.032 \\
\hline Divorced/widowed & $6(2.8)$ & $6(100)$ & \\
\hline \multicolumn{4}{|l|}{ Educational level } \\
\hline Illiterate & $34(15.8)$ & $13(38.23)$ & \\
\hline Primary & $58(27.0)$ & $27(46.6)$ & 0.12 \\
\hline Intermediate & $49(22.8)$ & $30(61.2)$ & \\
\hline Secondary & $57(26.5)$ & $27(47.4)$ & \\
\hline More than secondary & $17(7.9)$ & $5(29.41)$ & \\
\hline
\end{tabular}

$S D=$ standard deviation. 


\begin{tabular}{|c|c|}
\hline Prevalence $(n=215)$ & $n(\%)$ \\
\hline $\begin{array}{l}\text { Experienced khat chewers } \\
\text { Current khat chewers }\end{array}$ & $\begin{array}{l}141(65.6) \\
102(47.4)\end{array}$ \\
\hline Pattern of khat chewing (n=102) & \\
\hline $\begin{array}{l}\text { Age at starting khat chewing (yr) } \\
\text { Mean (SD) } \\
\text { Median } \\
\leq 15 \\
16-20 \\
>20\end{array}$ & $\begin{array}{l}23.1(7.1) \\
20.0 \\
18(17.6) \\
35(34.4) \\
49(48.0)\end{array}$ \\
\hline $\begin{array}{l}\text { Reason/s for continuing khat chewing } \\
\text { Increase alertness and concentration } \\
\text { Taste } \\
\text { Increase energy } \\
\text { Makes me feel refreshed } \\
\text { Increase self esteem and sexual desire } \\
\text { I am addictive and use it to prevent withdrawal symptoms of khat } \\
\text { Promote dialogue and social discussion } \\
\text { Others }\end{array}$ & $\begin{array}{l}37(36.3) \\
12(11.8) \\
48(47.1) \\
56(54.9) \\
9(8.8) \\
9(8.8) \\
81(79.4) \\
9(8.8)\end{array}$ \\
\hline $\begin{array}{l}\text { Frequency of chewing khat } \\
1-2 \mathrm{~d} / \mathrm{mo} \\
1 \mathrm{~d} / \mathrm{wk} \\
2-4 \mathrm{~d} / \mathrm{wk} \\
\text { Daily }\end{array}$ & $\begin{array}{c}21(20.6) \\
39(38.2) \\
30(29.4) \\
12(11.8)\end{array}$ \\
\hline $\begin{array}{l}\text { Cost of khat chewing /month } \\
\text { Median (range) (SR) } \\
\text { Median (range) (USD) } \\
\leq 500 \text { (SR) } \\
501-1000 \text { (SR) } \\
>1000 \text { (SR) }\end{array}$ & $\begin{array}{l}600(60-5000) \\
160(16-1334) \\
29(28.4) \\
48(47.1) \\
25(24.5)\end{array}$ \\
\hline $\begin{array}{l}\text { Quantity in g/session } \\
<300(<\text { bundle) } \\
300-500 \text { (bundle) } \\
>500 \text { (>bundle) }\end{array}$ & $\begin{array}{c}87(85.3) \\
9(8.8) \\
6(5.9)\end{array}$ \\
\hline $\begin{array}{l}\text { Duration in } \boldsymbol{h} / \text { session } \\
\quad<3 \\
3-5 \\
>5\end{array}$ & $\begin{array}{l}25(24.5) \\
65(63.7) \\
12(11.8)\end{array}$ \\
\hline $\begin{array}{l}\text { Other materials taken during chewing } \text { khat }^{a} \\
\text { Shisha } \\
\text { Cigarette smoking } \\
\text { Energy drinks } \\
\text { Sweet drinks } \\
\text { Others (cola, black tea, ice water) }\end{array}$ & $\begin{array}{l}31(30.4) \\
42(41.2) \\
43(42.2) \\
35(33.3) \\
26(25.5)\end{array}$ \\
\hline Family member share khat chewing & $54(52.9)$ \\
\hline $\begin{array}{l}\text { Frequency of family conflicts due to khat chewing } \\
\text { Nothing } \\
\text { 1 or } 2 \text { times } \\
\text { 3-9 times } \\
\geq 10 \text { times }\end{array}$ & $\begin{aligned} 72 & (70.6) \\
17 & (16.7) \\
3 & (2.9) \\
10 & (9.8)\end{aligned}$ \\
\hline History of trial to quit chewing khat & $47(46.1)$ \\
\hline $\begin{array}{l}\text { Obstacles to quitting chewing } \text { khat }^{a} \\
\text { Social commitment } \\
\text { Peer pressure } \\
\text { Unwillingness (no motivation) } \\
\text { Need to kill time }\end{array}$ & $\begin{array}{r}76(74.5) \\
60(59.6) \\
28(28.3) \\
11(10.6)\end{array}$ \\
\hline
\end{tabular}

${ }^{a}$ Not mutually exclusive.

$S D=$ standard deviation; $S R=$ Saudi Riyal, $U S D=U S$ dollar. 
drivers spent from 501 to 1000 Saudi riyal per month on khat chewing. The majority $(85.3 \%)$ chewed $<300 \mathrm{~g} / \mathrm{ses}$ sion $(<1$ bundle) of khat. Almost twothirds of them (63.7\%) spent $3-5$ hours per session khat chewing. Among the participants, $42.2 \%, 41.2 \%$ and $33.3 \%$ reported taking energy drinks, smoking cigarettes and consuming sweet drinks, respectively, during khat chewing. Other family members shared khat chewing with $52.9 \%$ of them and $29.4 \%$ reported family troubles due to khat chewing. Less than half of drivers who were chewing khat (46.1\%) reported attempting to quit, and the most frequent obstacles to quitting were social commitment (74.5\%) and peer pressure (59.6\%).

Taxi drivers reported a significantly higher rate of khat chewing compared to bus and heavy goods vehicle drivers (58.6\% vs 39.8\%) (Table 3). The average working time for drivers chewing khat were significantly lower compared to nonchewers [7.11 (2.67) vs 8.13 (3.72) hours; $P<0.05]$. Furthermore, their average daily working hours $[4.53$ (1.88)] were significantly lower compared to those of nonchewing drivers [5.46 (2.63); $P<0.05]$. Meanwhile, the average night-time driving was not significantly associated with khat chewing. All the drivers who reported never using a seatbelt were khat chewers compared with only $34.3 \%$ of those who reported always using a seatbelt. The difference was highly significant $(P<0.001)$. History of having road traffic accidents was not significantly associated with khat chewing $(P=0.675)$. However, the average number of serious crashes was significantly higher among khat chewers compared to nonchewers [2.65 (1.45) vs $1.97(0.87) ; P=0.01]$. Traffic violations in the previous month were significantly more frequently reported among khat chewers than nonchewers ( $72.7 \%$ vs $27.3 \% ; P=0.012$ ). Moreover, $47.7 \%$ of the khat chewers with a history of road traffic accidents admitted that khat chewing may have been a contributory factor. About $47.1 \%$ of the drivers admitted that khat chewing impaired their working ability on the day after a khat chewing session, to different extents (always, usually or sometimes).

Table 4 summarizes the results of multiple logistic regression analysis for predictors of khat chewing among drivers in Jazan Region. Being Saudi drivers was the highest predictor for khat chewing $(O R=7.53)$. Divorced or widowed drivers had almost double the risk for chat chewing compared to single drivers $(O R=2.03)$. Drivers who worked $>12$ hours/day were less likely to chew khat compared to those who worked for $\leq 4$ hours $(O R=0.23)$. Drivers who never used a seatbelt while driving had a 4-fold higher likelihood of chewing khat compared to those who always used a seatbelt $(\mathrm{OR}=4.04)$.

\section{Discussion}

The present study showed that about half of the drivers (47.4\%) in Jazan Region were current khat chewers. This was in conformity with the previously reported prevalence of khat use among the general population in Jazan Region (48.7\%) (5). It was surprising to find in the present study that khat chewing was not significantly affected by the level of education. This indicates that the availability of adequate income to purchase khat and motivating factors for khat use are more important than the level of awareness of its effects.

In the present study, the most frequent reasons for continuing chewing khat were promoting dialogue and social discussion, making the chewer feel refreshed, more energetic, alert and attentive. Similar claims of positive physiological aspects to khat chewing and strong energizing effect of workers have been reported elsewhere (3). For Yemenis, khat may be less of a drug than a medium for socialization (23).

The significantly higher prevalence of khat chewing among divorced or widowed drivers in the current study is explained by the ability of the psychoactive leaves to give temporary relieve from fatigue, loss of excitation, and sleep (24). Also, in the light of the current study, khat chewing has been reported to increase family conflicts and consequently may be implicated in divorces.

In the present study, drivers who worked for longer hours were less likely to chew khat compared to other drivers even after control of other confounders. Moreover, about half of them reported that khat chewing impair their working ability on the day after khat chewing. The drivers' claims that khat chewing increases alertness and concentration in the present study is contrary to previous findings (11) that some khat chewers experience anxiety, tension, restlessness, hypnologic hallucinations, hypomania and aggressive behaviour or psychosis, and consequently they are unable to work for long duration.

In the present study, the median age for starting khat chewing was 20 years and only $17.6 \%$ of the respondents initiated khat chewing at age $\leq 15$ years. However, in a study conducted in Ethiopia, $36.4 \%$ of people reported that the age of onset of khat chewing was $10-15$ years (25) and the median age of onset reported from Agaro and Gondar was 14.6 and 16.4 years, respectively $(25,26)$. Many factors increase the risk of khat chewing during adolescence, including socioeconomic status, neighbourhood, cultural context, peer influence, teachers' influence and perhaps most importantly, family influences (27). It is reported that social acceptability of khat chewing and socialization of this habit increase the likelihood of adolescents adopting the behaviour in Jazan Region (28). This fall in the age of initiation of khat chewing indicates the failure of prevention strategies (29).

More than $40 \%$ of the respondents in the present study reported cigarette smoking and having energy drinks with khat chewing. This finding is in line with other studies in Ethiopia and Somalia $(2,4)$. A study in Gondar, Ethiopia has 


\begin{tabular}{|c|c|c|c|c|}
\hline Work impacts & $\begin{array}{c}\text { Total } \\
(n=215)\end{array}$ & $\begin{array}{c}\text { Nonchewer } \\
(n=113) \\
n(\%)\end{array}$ & $\begin{array}{l}\text { Current chewers } \\
\left(\begin{array}{c}(n=102) \\
n(\%)\end{array}\right.\end{array}$ & $P$-value \\
\hline \multicolumn{5}{|l|}{ Type of vehicle } \\
\hline Taxi & 87 & $36(41.4)$ & $51(58.6)$ & \multirow[t]{2}{*}{0.023} \\
\hline Bus/heavy goods vehicle & 128 & $77(60.2)$ & $51(39.8)$ & \\
\hline Work duration (yr) & 91 & $46(50.5)$ & $45(49.5)$ & \multirow[t]{4}{*}{0.203} \\
\hline$\leq 5$ & 68 & $32(47.1)$ & $36(52.9)$ & \\
\hline $6-10$ & 56 & $35(62.5)$ & $21(37.5)$ & \\
\hline \multicolumn{4}{|l|}{$>10$} & \\
\hline \multicolumn{5}{|l|}{ Average working time $(h / d)$ mean (SD) } \\
\hline$\leq 4$ & 39 & $8.13(3.72)$ & $7.11(2.67)$ & \multirow[t]{2}{*}{0.024} \\
\hline $5-8$ & 107 & $23(59.0)$ & $16(41.0)$ & \\
\hline $9-12$ & 55 & $45(42.1)$ & $62(57.9)$ & \multirow[t]{3}{*}{$<0.001$} \\
\hline \multirow[t]{2}{*}{$>12$} & 14 & $31(56.4)$ & $24(43.6)$ & \\
\hline & & $14(100)$ & $0(0.0)$ & \\
\hline \multicolumn{5}{|l|}{ Average daytime driving time $(h)(n=198)$ mean $(S D)$} \\
\hline$\leq 4$ & & $5.46(2.63)$ & $4.53(1.88)$ & \multirow[t]{2}{*}{0.006} \\
\hline $5-8$ & 82 & $42(51.2)$ & $40(48.8)$ & \\
\hline \multirow{2}{*}{$>8$} & 108 & $58(53.7)$ & $50(46.3)$ & \multirow[t]{2}{*}{0.029} \\
\hline & 8 & $8(100)$ & $0(0.0)$ & \\
\hline \multicolumn{2}{|l|}{ Average night time driving $(h)(n=183)$ mean (SD) } & $4.39 \pm 2.26$ & $3.53 \pm 2.56$ & \multirow[t]{2}{*}{0.39} \\
\hline$\leq 4$ & 133 & $69(51.9)$ & $64(48.1)$ & \\
\hline $5-8$ & 44 & $21(47.7)$ & $23(52.3)$ & \multirow[t]{2}{*}{0.891} \\
\hline$>8$ & 6 & $3(50.0)$ & $3(50.0)$ & \\
\hline \multicolumn{5}{|l|}{ Use of seat belt } \\
\hline Always & 70 & $46(65.7)$ & $24(34.3)$ & - \\
\hline Usually & 52 & $34(65.4)$ & $18(34.6)$ & - \\
\hline Sometimes & 53 & $17(32.1)$ & $36(67.9)$ & - \\
\hline Rarely & 31 & $16(51.6)$ & $15(48.4)$ & \multirow[t]{2}{*}{$<0.001$} \\
\hline Never & 9 & $0(0.0)$ & $9(100)$ & \\
\hline$R T A^{a}$ & 77 & $39(50.6)$ & $38(49.9)$ & 0.675 \\
\hline Average major RTA ${ }^{\mathrm{b}}$ & & $1.97(0.87)$ & $2.65(1.45)$ & 0.01 \\
\hline Traffic violations ${ }^{c}$ & 22 & $6(27.3)$ & $16(72.7)$ & 0.012 \\
\hline Reduced ability to work on the day after khat & - & - & - & - \\
\hline chewing ${ }^{d}$ & - & - & - & - \\
\hline Always & - & - & $6(5.9)$ & - \\
\hline Usually & 102 & - & $9(8.8)$ & - \\
\hline Sometimes & - & - & $33(32.4)$ & - \\
\hline Rarely & - & - & $20(19.6)$ & - \\
\hline Never & - & - & $34(33.3)$ & - \\
\hline Khat chewing cause of RTA (yes/possible) ${ }^{d}$ & 38 & - & $18(47.4)$ & - \\
\hline Khat chewing cause of violations (yes/possible) d & 16 & - & $1(6.3)$ & - \\
\hline
\end{tabular}

${ }^{a}$ Working history of RTA. ${ }^{b}$ Reportable, causing fractures, disability or loss of life. CHistory of traffic violation in the previous month. ${ }^{d}$ Among khat chewers only. RTA = road traffic accident; $S D=$ standard deviation.

also shown that smoking is common and accompanies khat chewing (30). Traditionally, cigarette smoking and energy drinks accompany khat chewing in order to achieve maximum excitement (4).
In the current study, khat chewing was significantly associated with road traffic accidents, and nearly half of the drivers involved stated that chewing khat may have been a possible cause of these crashes. Khat chewing was also significantly associated with a higher rate of traffic violations and significantly poorer compliance with wearing seat belts. All these factors may act together to make road traffic accidents more severe among khat chewers. Research 


\begin{tabular}{|c|c|c|c|}
\hline & Adjusted OR & $(95 \% \mathrm{Cl})$ & $P$ value \\
\hline \multicolumn{4}{|l|}{ Nationality } \\
\hline Saudi ( $n=178)$ & 7.53 & $4.21-47.96$ & 0.00 \\
\hline Non-Saudi $(n=37)$ & Ref & - & \\
\hline \multicolumn{4}{|l|}{ Marital status } \\
\hline Single $(n=19)$ & Ref & - & \\
\hline Married $(n=190)$ & 0.96 & $0.32-6.25$ & 0.359 \\
\hline Divorced/widowed ( $n=6)$ & 2.03 & $1.08-21.02$ & 0.013 \\
\hline \multicolumn{4}{|l|}{ Average working time $(h / d)$} \\
\hline$\leq 4(n=39)$ & Ref & - & \\
\hline $5-8(n=107)$ & 1.42 & $0.62-4.29$ & 0.459 \\
\hline $9-12(n=55)$ & 1.09 & $0.33-6.02$ & 0.525 \\
\hline$>12(n=14)$ & 0.23 & $0.09-0.56$ & 0.022 \\
\hline \multicolumn{4}{|l|}{ Use of seat belt } \\
\hline Always ( $n=70)$ & Ref & - & \\
\hline Usually $(n=52)$ & 1.02 & $0.12-3.29$ & 0.458 \\
\hline Sometimes $(n=53)$ & 2.66 & $0.73-4.02$ & 0.152 \\
\hline Rarely $(n=31)$ & 1.86 & $0.42-6.22$ & 0.336 \\
\hline Never $(n=9)$ & 4.04 & $1.02-12.02$ & 0.002 \\
\hline
\end{tabular}

Terms of type of vehicle, religion and average daytime driving time were removed from the final logistic regression model (not significant). $C I=$ confidence interval; $O R=$ odds ratio; $R$ ef $=$ reference group.

on African/Middle Eastern drivers stopped by German police on suspicion of driving under the influence of drugs has found that driving ability is severely impaired by khat consumption (31). Also, qualitative research from Ethiopia has found that chewing khat is a major contributor to road traffic accidents, and hence potential fatalities, and are related to the fact that khat increases driver confidence and vehicle speed, thus making drivers irritable, with impaired concentration and misplaced sense of alertness (21). The impaired working ability on the day after a khat chewing session reported by most of the drivers in the current study may play a role in increasing the risk and severity of road traffic accidents (21).

In the current study, the median monthly cost of khat chewing was 600 Saudi riyal (US\$160). This represent money that could have been spent on other beneficial purposes. The average working hours for khat-chewing drivers were significantly lower than for nonchewers. Additionally, khat chewing was associated with loss of working hours and most of the chewers spent a long time (3-5 hours) chewing khat on $>1$ day/week. A considerable percentage of them reported work impairment on the next day after a chewing session. These results are in conformity with other studies that have indicated that khat chewing is associated with signifcant economic loss due to the cost of khat chewing, impaired working ability in a highly productive age group, and suppressed occupational motivation (3, $12,32,33)$.

In the social domain, the current study revealed that almost a third of khat chewing drivers reported family conflicts, and on more than half of these occasions, other family members were also involved in khat chewing. Previous studies have indicated that family disruption is a prominent problem associated with khat chewing, which includes frequent quarrels, breach of family ties, neglect of the education and care of children, waste of family resources, encouragement of prostitution and encouragement of family members to become involved in khat chewing (2).
About half of the khat-chewing drivers reported failed attempts to quit, with the most frequent obstacles being social commitment and peer pressure. Peer pressure always plays a major role in drug abuse and smoking initiation (34-35). One study showed that negative peer pressure was a factor in the initiation of khat use and hindered quitting (29). Also, the presence of social dependence and community acceptance and absence of khat chewing stigmatization may make quitting difficult.

The strengths of the current study include that it is believed to be the first study among professional drivers to identify the magnitude and predictors of khat chewing, its relation to traffic accidents and violations, and its socioeconomic impacts. However, this study had a few limitations that should be mentioned. First, we relied on past history data to address the problem, which could have biased the results of the impact of khat chewing. Second, data collection depended mainly on self-reporting, although every effort was made to minimize any possible over- or 
under-reporting by the participants. Third, because this was a cross-sectional study, the temporality of the associations between khat chewing and the related problems cannot be certain and it is difficult to confirm a causal relationship. Also, being a cross-sectional design gives only a current snapshot of the problem that may be different if the time-frame were changed.

\section{Conclusion}

According to the present study, khat chewing habit affects almost half of the professional drivers in Jazan Region. There were some associations between khat chewing and work impairment, driving-related problems, as well as some behavioural and social impacts. Longitudinal and experimental studies are necessary to investigate the mechanisms that might cause these associations. There should be coordination between different community partners in Jazan Region including health practitioners, religious leaders, educationalists and social leaders to establish programmes to combat khat chewing to tackle and stigmatize this deeply rooted social problem.

\section{Funding: None.}

Competing interests: None declared.

\section{References}

1. Luqman W, Danowski TS. The use of khat (Catha edulis) in Yemen: social and medical observations. Ann Intern Med. 1976 Aug;85(2):246-9. PMID:942147

2. Elmi AS. The chewing of khat in Somalia. J Ethnopharmacol. 1983 Aug;8(2):163-76. PMID:6139513

3. Ageely HM. Health and socioeconomic hazards associated with khat consumption. J Family Community Med. 2008 Jan;15(1):1-9. PMID:23012161

4. National Drug Intelligence Center. Intelligence bulletin: khat (Catha edulis). Johnstown, PA: NDIC; 2003 (http://www. justice.gov/ndic/pubs3/3920/index.htm, accessed 14 February 2017)

5. Milaat AA, Bani IA, Ageely HM, El-Naggar MM. Assessment of Health risk factors and social problems associated with Khat use in Jazan region. Project research report, King Abdulaziz University, Jazan, Saudi Arabia; 2006.

6. Varisco DM. On the meaning of chewing: the significance of Khat (Catha edulis) in the Yemen Arab Republic. Int J Middle East Stud. 1986 Feb;18(1):1-13.

7. Ageely HM. Prevalence of Khat chewing in college and secondary (high) school students of Jazan region, Saudi Arabia. Harm Reduct J. 2009 Jun 20;6:11. PMID:19545389

8. Numan N. Exploration of adverse psychological symptoms in Yemeni khat users by the Symptoms Checklist-90 (SCL-90). Addiction. 2004 Jan;99(1):61-5. PMID:14678063

9. Kalix P. The pharmacology of khat. Gen Pharmacol. 1984;15(3):179-87. PMID:6376274

10. Hassan NA, Gunaid AA, Abdo-Rabbo AA, Abdel-Kader ZY, al-Mansoob MA, Awad AY et al. The effect of khat chewing on blood pressure and heart rate in healthy volunteers. Trop Doct. 2000 Apr;30(2):107-8. PMID:10842563

11. Yousef G, Huq Z, Lambert T. Khat chewing as a cause of psychosis. Br J Hosp Med. 1995 Oct 4-7;54(7):322-6. PMID:8556211

12. Dhadphale M, Omolo OE. Psychiatric morbidity among khat chewers. East Afr Med J. 1988 Jun;65(6):355-9. PMID:3181055

13. Al-Motarreb AL, Broadley KJ. Coronary and aortic vasoconstriction by cathinone, the active constituent of khat. Auton Autacoid Pharmacol. 2003 Oct-Dec;23(5-6):319-26. PMID:15255816

14. Al-Motarreb S, Briancon N, Al-Jaber B, Al-Adhi F, Al-Jailani MS, Salek KJ. Khat chewing is a risk factor for acute myocardial infarction: a case-control study. Br J Clin Pharmacol. 2005 May;59(5):574-81. PMID:15842556
15. Al-Hadrani AM. Khat induced Haemorrhoidal disease in Yemen. Saudi Med J. 2000 May;21(5):475-7. PMID:11500685

16. Abdul-Ghani NA, Eriksson M, Kristiansson B, Qirbi AA. The influence of Khat chewing on birth weight in full term infants. Soc Sci Med. 1987;24(7):625-7. PMID:3589757

17. Eriksson M, Abdul-Ghani NA, Eriksson M, Kristiansson B. Khat chewing during pregnancy and some characteristics of the chewers. East Afr Med J. 1991 Feb;68(2):106-11. PMID:2040229

18. Al-Hebshi NN, Skaug N. Effect of Khat chewing on 14 selected periodontal bacteria in sub- and supragingival plaque of a young male population. Oral Microbiol Immunol. 2005 Jun;20(3):141-6. PMID:15836514

19. Corkery JM, Schifano F, Oyefeso A, Ghodse AH, Tonia T, et al. Bundle of fun' or 'bunch of problems'? Case series of khat-related deaths in the UK. Drugs Educ Prev Policy. 2011;18(6):408-25.

20. Ansari S, Akhdar F, Mandoorah M, Moutaery K. Causes and effects of road traffic accidents in Saudi Arabia. Public Health. 2000 Jan;114(1):37-9. PMID:10787024

21. Eckersley W, Salmonb R, Gebru M. Khat, driver impairment and road traffic injuries: a view from Ethiopia. Bull World Health Organ. 2010 Mar;88(3):235-6. PMID:20428394

22. Swanson WH, Cohen JM. Color vision. Ophthalmol Clin North Am. 2003 Jun;16(2):179-203. PMID:12809157

23. Lqman W, Donaldson T. The use of Khat (Catha edulis) in Yemen. Social and medical observations. Ann Intern Med. 1976 Aug;85(2):246-9. PMID:942147

24. Megerssa B, Esayas A, Mohamed A. Socio-economic impact of khat in Mana District, Jimma Zone, South Western Ethiopia. Agricultural Science. Engineering and Technology Research. 2013;1(4):44-59.

25. Kebede Y. Cigarette smoking and khat chewing among college students in Northwest Ethiopia. Ethiop J Health Dev. 2002;16(1):9-17 (http://www.ajol.info/index.php/ejhd/article/view/9818/31243)

26. Fekade A, Challi J, Tadesse M. Khat chewing among Agaro secondary school students. Ethiop Med J. 1994 Jul;32(3):161-6. PMID:7957128

27. Johnson V, Pandina RJ. Effects of the family environment on adolescent substance use, delinquency, and coping styles. Am J Drug Alcohol Abuse. 1991;17(1):71-88. PMID:2038985

28. Mahfouz MS, Alsanosy RM, Gaffar AM. The role of family background on adolescent khat chewing behavior in Jazan Region. Ann Gen Psychiatry. 2013 May;12(1):16. PMID:23688046 
29. Alsanusy R, El-Setouhy M. Why would khat chewers quit? An in-depth, qualitative study on Saudi khat quitters. Subst Abus. 2013;34(4):389-95. PMID:24159910

30. Zein A. Polydrug abuse among Ethiopian university students with particular reference to khat. In: Dagne E, editor. International Symposium on Khat (Catha edulis), Addis Ababa, Ethiopia, December 15, 1984. Natural Products Research Network for Eastern and Central Africa; 1984:85-9.

31. Toennes SW, Kauert GF. Driving under the influence of khatalkaloid concentrations and observations in forensic cases. Forensic Sci Int. 2004 Feb;140(1):85-90. PMID:15013169

32. Gelaw Y, Haile-Amlak A. Khat chewing and its socio-demographic correlates among the staff of Jimma University. Ethiop
J Health Dev. 2004;18(3):179-84 (http://www.ajol.info/index. php/ejhd/article/view/9957/31320).

33. Aden A, Dimba EA, Ndolo UM, Chindia ML. Socio-economic effects of khat chewing in north eastern Kenya. East Afr Med J. 2006 Mar;83(3):69. PMID:16771102

34. Reda AA, Moges A, Biadgilign S, Wondmagegn BY. Prevalence and determinants of khat (Catha edulis) chewing among high school students in eastern Ethiopia: a cross-sectional study. PLoS One. 2012;7(3):e33946. PMID:22479484

35. Feigin A, Higgs $P$, Hellard M, Dietze P. The impact of khat use on East African communities in Melbourne: a preliminary Investigation. Drug Alcohol Rev. 2012 May;31(3):288-93. PMID:21463373 